\title{
One-stage reconstruction with open bone grafting and vacuum-assisted closure for infected tibial non-union
}

Zhouming Deng, Lin Cai, Wei Jin, Ansong Ping, Renxiong Wei

Department of Orthopaedics, Zhongnan Hospital of Wuhan University, Wuhan, China

Submitted: 29 February 2012

Accepted: 14 June 2012

Arch Med Sci 2014; 10, 4: 764-772

DOI: 10.5114/aoms.2013.34411

Copyright @ 2014 Termedia \& Banach

\section{Abstract}

Introduction: Non-union of the tibia complicated by osteomyelitis is one of the most challenging problems in orthopaedic surgery. There remains a significant amount of debate and controversy regarding the optimal medical management of infected tibial non-union. There are few articles which have reported the outcomes of treatment for infected non-union of tibia from single-stage reconstruction with open bone grafting plus vacuum-assisted closure (VAC).

Material and methods: Our report covers experience between March 2007 and February 2010 of open bone grafting plus VAC in one stage for patients with infected tibial non-union. The time for bone union and wound healing to occur, the duration of hospitalisation, and the rate of resolution of infection were all analysed. The main outcome measures were based on a clinical scoring system that assessed functional ability, range of knee and ankle motion, shortening, infection and pain. Fifteen patients were involved in this study.

Results: All patients were followed up for an average of 22.6 months (range: 14-42 months). Bone union was achieved in $93.3 \%$ (14/15) of patients after a mean of 5.93 months (range: 3-10 months). All wounds healed within an average period of 5 weeks (range: 3-10 weeks), and the function and appearance of all limbs were satisfactory.

Conclusions: Open bone grafting combined with VAC in a one-stage procedure can be a feasible alternative to the treatment of infected tibial non-union, especially for those wounds which are not good candidates for microsurgery; however, further studies are required to confirm the likely benefits.

Key words: vacuum-assisted closure, Papineau technique, tibial non-union, infected.

\author{
Correspondence author: \\ Lin Cai MD \\ Department of Orthopaedics \\ Zhongnan Hospital \\ of Wuhan University \\ No. 169 Donghu Road \\ 430071 Wuhan \\ Hubei Province, China \\ Phone: 8627-67813116 \\ Fax: 8627-67813116 \\ E-mail: \\ guke3559@yahoo.com.cn
}

\section{Introduction}

Non-union of tibial shaft fractures is generally considered to be the most frequently observed type of long-bone non-union [1]. This is due to the high incidence of severe, open tibial fractures caused by motor vehicle accidents, which are usually unstable and/or comminuted, often with extensive damage of the surrounding soft tissue, and accompanying neurovascular damage. An infected non-union adds complexity, because dead bone lies within a compromised soft-tissue envelope. Despite new techniques and improvements in management, the infection of tibial nonunions remains one of the toughest challenges for orthopaedic and plastic surgeons. One method for curing infective tibial non-union is open bone grafting, which was introduced by Papineau [2]. The Papineau technique involves radical, open bone debridement, with the grafting of cancellous bone over a granulation tissue base, delayed soft tissue closure, and immo- 
bilization of the affected extremity. As technology and free-tissue transfer methods have evolved, the technique has been abandoned or adapted to modern wound care techniques [3]. For example, Saleh et al. [4] and Emami et al. [5] modified the Papineau technique with the application of external fixators. Archdeacon and Messerschmitt [3] have reported a modern Papineau technique with vacuum-assisted closure (VAC). In a study of four patients, they performed open cancellous bone grafting in two stages, after first obtaining a clean wound bed by application of VAC for several days. There is, however, limited literature regarding the treatment of infected tibial non-unions using combined, singlestage open bone grafting and VAC. In this paper, we report the results of this technique for treating infected tibial non-unions. This research was approved by the Committee on Ethics of Medicine Research of our hospital.

\section{Material and methods}

Between March 2007 and February 2010, 15 consecutive patients with infected tibial non-unions were treated at our institution. The average age of the 15 patients was 44.5 years (range: $24-68$ years), and there were 9 men and 6 women. In all 15 patients, the aetiology of the infected tibial non-union was a severe fracture arising from motor vehicle accidents. Two patients had had closed tibial fractures, whilst the other 13 patients had had open fractures. The mean time since the onset of tibial infection was 9.1 months (range: 3-18 months). In three cases the infection was located in the proximal third of the tibia; in a further five cases it was located in the middle third; and in the remaining seven cases the infection was located in the distal third of the tibia. All patients had undergone previous surgery for established infection and antibiotic treatment at their primary treating hospital (mean number of procedures: 3.7; range: 1-7). The technique of primary fixation of the tibial fracture varied among the 15 patients (Table I). Most of the patients suffered from varying degrees of stiffness in their knee or ankle joints.

Prior to undergoing the procedure, all patients underwent routine work-up, including a full blood count, erythrocyte sedimentation rate (ESR), and C-reactive protein (CRP) levels to determine the intensity of infection. In addition, the patients underwent $X$-ray and CT imaging to provide data on: (1) the site and type of fractures; (2) the presence or absence of a sequestrum; and if present, its site and size; (3) operative approaches; (4) the size of any bone defects and estimates of the amount of bone grafting; and (5) bone density and stability. Diagnosis of infected tibial non-union was made on the basis of clinical presentation, imaging and laboratory data (including white cell counts, ESR and (RP), and the presence of positive microbiological cultures from specimens collected during our procedure.

Table I. Clinical data of 15 patients with infected tibial non-union

\begin{tabular}{|ccccccccc|}
\hline Patient & $\begin{array}{c}\text { Age } \\
\text { [years] }\end{array}$ & Gender & $\begin{array}{c}\text { Fracture } \\
\text { type } \\
\text { (Gustilo) }\end{array}$ & $\begin{array}{c}\text { Initial } \\
\text { treatment }\end{array}$ & $\begin{array}{c}\text { Duration of bone } \\
\text { infection } \\
\text { [months] }\end{array}$ & $\begin{array}{c}\text { Soft-tissue } \\
\left.\text { defect [cm }{ }^{2}\right]\end{array}$ & $\begin{array}{c}\text { Number of } \\
\text { previous tibial } \\
\text { operations }\end{array}$ & $\begin{array}{c}\text { Accompanying } \\
\text { fractures }\end{array}$ \\
\hline 1 & 24 & F & Oll & EF + VAC & 6 & $1 \times 3$ & 4 & None \\
\hline 2 & 32 & M & Ollla & EF + VAC + KW & 18 & $3 \times 3$ & 7 & IL (FB, MM) \\
\hline 3 & 56 & M & Ol & EF & 6 & $2 \times 4$ & 2 & Cl (FB) \\
\hline 4 & 29 & M & Olllb & EF + VAC + KW & 3 & $1 \times 1$ & 1 & IL (LM) \\
\hline 5 & 68 & F & Oll & EF + VAC + KW & 11 & $1 \times 4$ & 6 & IL (FM, FB) \\
\hline 6 & 35 & F & C & IN & 7 & $3 \times 5$ & 5 & None \\
\hline 7 & 47 & M & Oll & EF + VAC & 9 & $1 \times 2$ & 4 & None \\
\hline 8 & 32 & M & C & IN + KW & 8 & $5 \times 12$ & 4 & IL (FB, MM) \\
\hline 9 & 51 & M & Oll & EF & 5 & $2 \times 6$ & 2 & IL (FB, LM), Cl (LM) \\
\hline 10 & 67 & F & OIlla & EF + VAC + KW & 9 & $1 \times 1$ & 3 & IL (FM, FB, LM) \\
\hline 11 & 38 & F & Ol & IN + KW & 12 & $1 \times 3$ & 4 & IL (FB) \\
\hline 12 & 42 & F & Oll & PF & 11 & $3 \times 4$ & 3 & IL (FB) \\
\hline 13 & 61 & M & Oll & EF + VAC & 7 & $3 \times 7$ & 1 & IL (FB, LM, MM) \\
\hline 14 & 45 & M & Ol & EF & 9 & $2 \times 4,3 \times 9$ & 4 & None \\
\hline 15 & 40 & M & Oll & EF + VAC & 16 & $1 \times 3$ & 5 & IL (FB, LM, MM) \\
\hline
\end{tabular}

$C$ - closed fracture, $C l$-contralateral, EF- external fixation, $F$ - female, FB - fibula, FM - femur, IN-intramedullary nail, IL - ipsilateral, KW Kirschner wire, $L M$ - lateral malleolus, $M$ - male, MM - medial malleolus, OI - type I open fracture, OII - type II open fracture, OIIIa - type IIIa open fracture, OIIIb - type IIIb open fracture, PF-plate fixation, VAC-vacuum-assisted closure 


\section{Operation methods}

All operations were performed under either continuous epidural anaesthesia or general anaesthesia. Sinus tracts or open wounds were thoroughly explored and subsequently irrigated with normal saline, and any old hardware was removed. The obvious sequestra and dead bone seen on the radiological imaging were removed, and the bone was resected to bleeding osseous tissue to ensure viability. Scarred ischaemic or necrotic subcutaneous tissues, deep fascia and muscle were also excised to obtain a healthy vascular bed. Healthy bone was then harvested from the iliac crest by osteotome, and then laid into the area of bony deficit. Deep swab cultures were taken. All patients except for case 4 were stabilised using external fixation, and the fixation was adjusted until lower limb alignment was as normal as possible. All open bone graft sites were then covered using VAC (Wuhan VSD Medical Science \& Technology Co., Ltd, Wuhan, Hubei, China), using the Hospital Central Negative Pressure system as the negative pressure source (150-350 mm Hg).

An intravenous broad-spectrum antibiotic (ceftriaxone) was started, but then changed to the most effective narrow-spectrum antibiotic (or combination of antibiotics) as soon as sensitivities were available from definitive cultures. The antibiotics depend on the results of cultures. For example, we give single aztreonam for Escherichia coli. The results of cultures, available in 15 patients, were as follows: oxacillinresistant Staphylococcus aureus (4), Pseudomonas (4), Escherichia coli (3), Streptococcus (2), Acinetobacter baumannii (1), mixed organisms (1). The duration of intravenous antibiotic therapy was based on microbiological studies of the intraoperative specimens as well as ESR and CRP levels, and the mean time was 2 weeks (range: 1-4 weeks). If there was no further evidence of infection in either the wound or radiographs, and ESR and CRP levels were within the normal range, patients were then prescribed further oral antibiotics for at least 2 weeks.

An airtight seal of the VAC dressing was maintained throughout, with the dressing re-sealed in the event of any leak. The VAC was changed every 7 days (except case 4) without disturbing the granulation tissue. This allowed wound inspection to evaluate the rate of ingrowth of granulation tissue into the scaffolding of the bone graft. Most papers recommend that the VAC should be changed every 3-7 days. However, a number of studies were reviewed by the authors of the Cochrane report [6], who felt that with the current literature it is still not possible to determine the optimum topical negative pressure regimen. The manufacturer (Wuhan VSD Medical Science \& Technology Co., Ltd, Wuhan, Hubei, China) recommended that the dressing should be changed every 5-7 days. Cancellous bone chips less than 5-mm thick can achieve the maximum diffusion distance of nutrients, which could promote the ability of anti-infection [7]. Therefore, in most cases, we changed the VAC sealing every 7 days (except case 4). In case 4, this patient had a bad compliance and economic condition. He refused the doctor's recommendations and insisted changing the VAC sealing every 14 days, and he signed informed refusal of treatment, due to the fact that changing the VAC sealing would cost about 2000 RMB. Even after we told him that it may result in longer persistence of bacteria, he still did not change his mind. The VAC was removed when the bone graft surface was completely covered with granulation tissue, and the wound was then allowed to heal using either a split-thickness skin graft or spontaneous epithelialization. The patients were followed up on a regular basis in the outpatient department at intervals of 4 to 6 weeks for clinical and radiological evaluation to assess the healing process. As radiological evidence of bone union emerged, patients were encouraged to progress to partial weight bearing using crutches. Full weight bearing was not permitted until the fracture site was fully healed. After fracture healing, patients were advised to attend follow-up once every 3 months, and whenever necessary. Bone union was defined clinically by the absence of mobility or pain, and the ability to ambulate without any aid. Radiographically it was defined by the presence of bridging callus formation on at least three cortices on orthogonal radiographs. The external fixation device remained in situ until bone union. The final outcome was evaluated clinically according to a scoring system described by Shahcheraghi and Bayatpoor [6], based on functional status, range of motion of the knee and ankle, presence of infection, shortening and pain (excellent 90-100, good 80-90, fair 70-79, and poor 60-69).

\section{Results}

All 15 patients were followed up for an average of 22.6 months (range: 14-42 months). The average length of bony defect after debridement was $3.9 \mathrm{~cm}$ (range: $2-8 \mathrm{~cm}$ ). In 14 patients skin cover was achieved through spontaneous epithelisation of granulation tissue; 1 patient (case 6) required a skin graft due to a large wound size. Wound healing occurred in a mean of 5 weeks (range: 3-10 weeks), and the mean number of VAC replacements was 3.6 (range: 2-8). Bone union was achieved in 14 of 15 patients at an average of 5.93 months (range: 3-10 months). One patient ended up with a tibial non-union with $30^{\circ}$ of varus (case 4 ), an increase on the $20^{\circ}$ of varus identified preoperatively. We attributed this failure to a shorter period of stabilization, against the doctor's orders. However, this patient was satisfied with the final out- 
come, and since he was able to return to gainful employment without any aids he did not want to undergo any further surgery. Two patients (cases 4 and 7) had a residual leg-length discrepancy (LLD), but these were not clinically significant. The average total length of hospitalisation for the $15 \mathrm{pa}$ tients was 3.6 months (range: 2-8 months).

All 15 patients were either very satisfied or satisfied with their outcome. According to the scoring system introduced by Shahcheraghi and Bayatpoor [8], there were seven excellent results, four good results, three fair results and one poor result. All 15 patient were able to walk without any aids, 12 patients were able to resume their previous level of activity, including participation in strenuous work and sports, and the other 3 patients were able to return to their deskwork of light activities.

There had been no re-fracture and no recurrences of osteomyelitis or residual infection at the last follow-up, and no patient required limb amputation. Minor pin-tract infection was observed in 2 patients, but the infection was controlled with pin-tract care. There was pin loosening in 1 patient; this was corrected by removing the loose pins and inserting replacements. There was no evidence of any iatrogenic neurological or vascular deficits, and no donor site morbidity was noted. The most common complication was stiffness of the ankle joint arising from transarticular immobilisation, but this improved after long-term rehabilitation guided by the attending physician. Leg shortening occurred in 2 patients $(1 \mathrm{~cm}$ and $1.5 \mathrm{~cm})$, but this discrepancy was largely present on arrival, and was due to debridement of the bone done at the initial operation. Patient details and the study results are shown in Table II. Figures 1 and 2 illustrate the results for 1 typical patient.

\section{Discussion}

Infected tibial non-union is a major therapeutic challenge, largely because these patients have usually undergone multiple previous surgical interventions, resulting in bone defects and soft tissue compromise [9]. The two major complications following an operation for infected non-union of the tibia are recurrent infections and lack of bone healing. Accordingly, treatment of infected non-union of the tibia requires a strategy for both curing the osteomyelitis and for creating an environment to support the healing of the reconstructed bone [10]. There are several treatment options available, including bone grafting [1, 11], bone stimulation [12] bone transport techniques $[13,14]$ and free tissue transfers $[15,16]$. However, given the lack of consensus in the medical literature on what is the most effective technique, it is obvious that all these modalities have limitations. Electrical stimulation for non-union has not yet shown results that are better than or consistently comparable to surgical treatment, and has proven to be ineffective in the presence of a significant defect (for example, an interfragmentary gap wider than one-half the diam-

Table II. Complete results of 15 patients with infected tibial non-union

\begin{tabular}{|c|c|c|c|c|c|c|c|c|c|c|}
\hline Patient & $\begin{array}{c}\text { Bone } \\
\text { defect } \\
{[\mathrm{cm}]}\end{array}$ & $\begin{array}{l}\text { Skin } \\
\text { graft }\end{array}$ & $\begin{array}{c}\text { Bone } \\
\text { union } \\
\text { time } \\
\text { [months] }\end{array}$ & $\begin{array}{c}\text { Wound } \\
\text { healing } \\
\text { time } \\
\text { [weeks] }\end{array}$ & $\begin{array}{l}\text { LLD } \\
{[\mathrm{cm}]}\end{array}$ & Limping & $\begin{array}{c}\text { Hospitalization } \\
\text { time } \\
\text { [months] }\end{array}$ & $\begin{array}{l}\text { Follow-up } \\
\text { [months] }\end{array}$ & $\begin{array}{l}\text { Final } \\
\text { score }\end{array}$ & $\begin{array}{l}\text { Subjective } \\
\text { satisfaction }\end{array}$ \\
\hline 1 & 5 & No & 3 & 4 & No & No & 2 & 16 & $E$ & VS \\
\hline 2 & 4 & No & 6 & 5 & No & No & 2 & 15 & $E$ & $S$ \\
\hline 3 & 3 & No & 8 & 3 & No & No & 3 & 42 & G & $\mathrm{S}$ \\
\hline 4 & 3 & No & No & 3 & 1 & Yes & 6 & 14 & $P$ & $\mathrm{~S}$ \\
\hline 5 & 2 & No & 7 & 6 & No & No & 3 & 18 & G & VS \\
\hline 6 & 3 & Yes & 10 & 7 & No & No & 8 & 27 & $\mathrm{~F}$ & VS \\
\hline 7 & 5 & No & 6 & 4 & 1.5 & No & 2 & 14 & $E$ & VS \\
\hline 8 & 6 & No & 8 & 10 & No & No & 4 & 36 & $E$ & $\mathrm{~S}$ \\
\hline 9 & 4 & No & 4 & 4 & No & No & 5 & 20 & $\mathrm{~F}$ & $\mathrm{~S}$ \\
\hline 10 & 8 & No & 4 & 6 & No & No & 4 & 19 & $E$ & $\mathrm{~S}$ \\
\hline 11 & 2 & No & 3 & 6 & No & No & 2 & 31 & $E$ & VS \\
\hline 12 & 4 & No & 9 & 4 & No & No & 6 & 15 & $E$ & $\mathrm{~S}$ \\
\hline 13 & 3 & No & 4 & 5 & No & No & 2 & 16 & G & $\mathrm{S}$ \\
\hline 14 & 5 & No & 6 & 5 & No & No & 3 & 33 & $\mathrm{~F}$ & VS \\
\hline 15 & 2 & No & 5 & 3 & No & No & 2 & 23 & G & VS \\
\hline
\end{tabular}

DS - dissatisfied, E-excellent, F-fair, G-good, P-poor, S-satisfied, VS - very satisfied 
eter of the bone at that level $[17,18])$. Bone transport has been used to treat infected tibial nonunion and has high rates of bone healing. However, this procedure is associated with significant disadvantages including the long treatment period, patient discomfort, and the need for a specialist
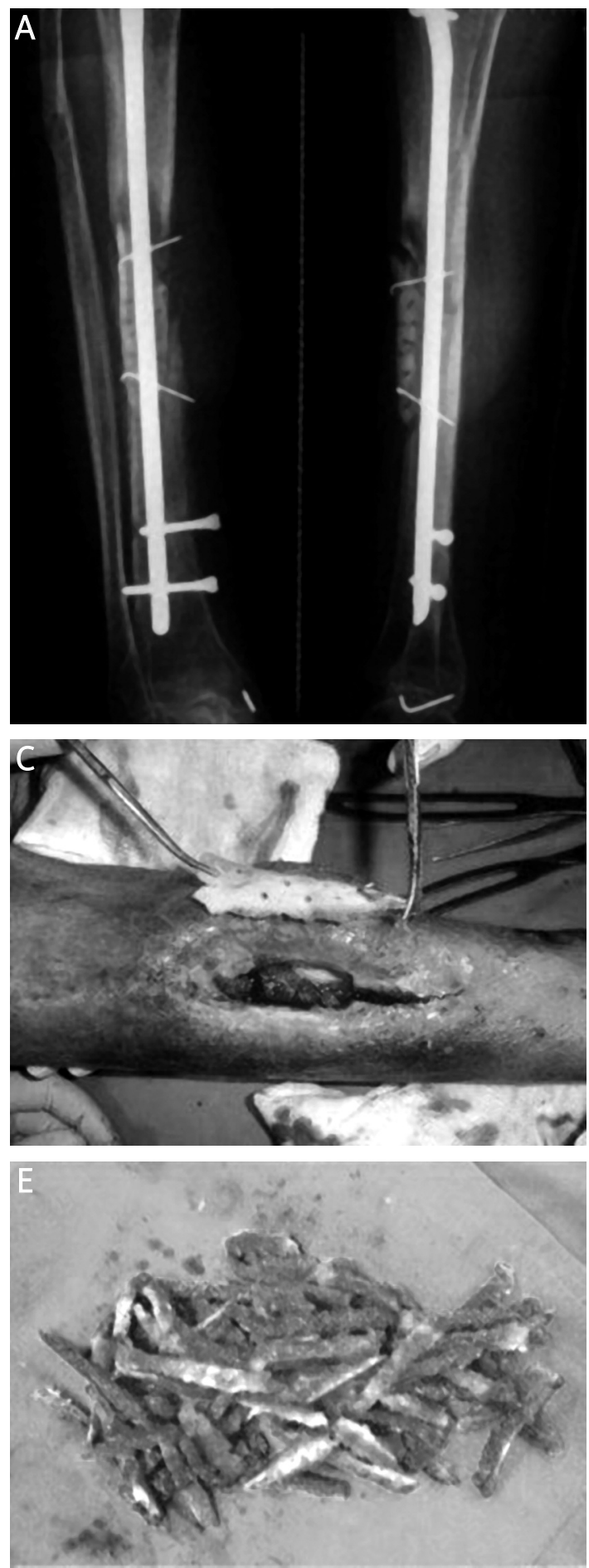

team with a multidisciplinary approach $[9,19]$. Additionally, Cattaneo et al. [19] reported that about onefifth $(5 / 28)$ of patients suffered recurrent postoperative drainage, with failure of the infection to resolve. Free tissue transfers, such as vascularised fibular grafts or microvascular muscle transplanta-
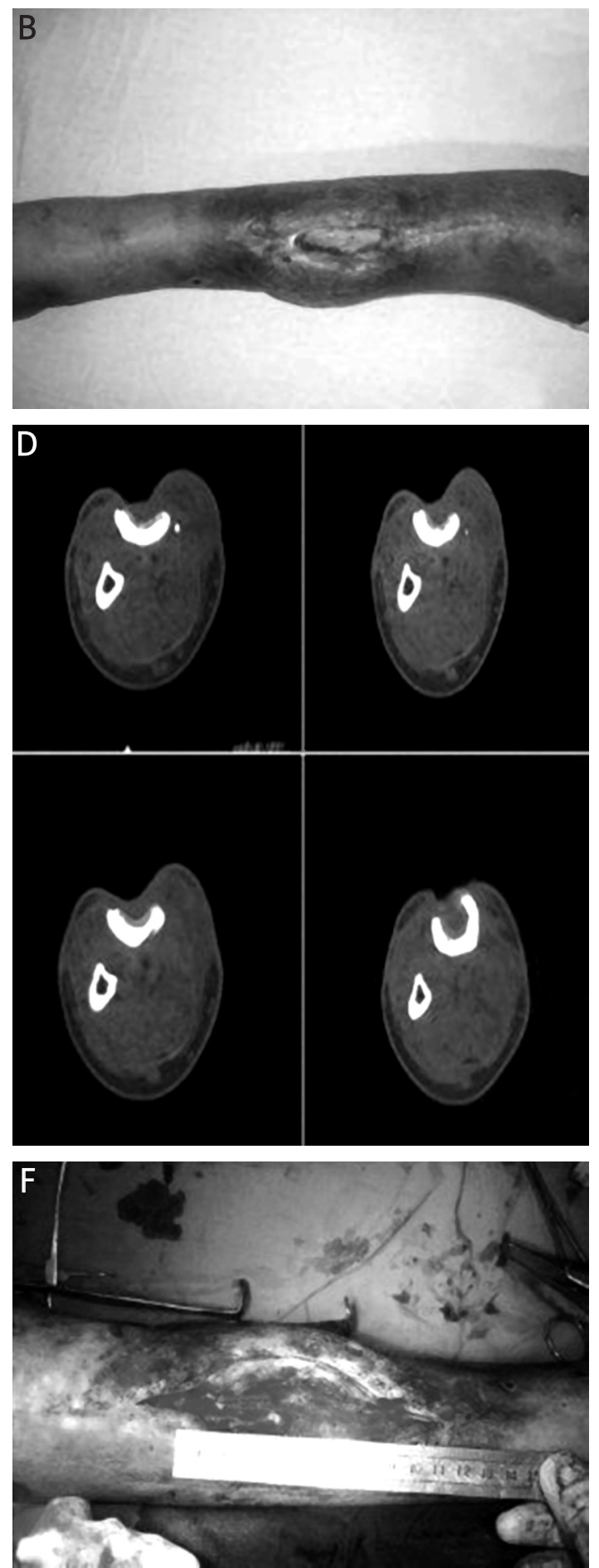

Figure 1. Case 8. A - The preoperative radiograph. B - The appearance before open bone grafting showing exposure of the tibia and wound infection. C - The sequestrum was excised. D - The CT scan clearly showed the dimension of the bony defect of the tibia. $\mathrm{E}$ - The autogenous ilium was fashioned into matchsticks. F- The iliac bone was grafted into the site of the defect, which measured about $6 \mathrm{~cm}$ 

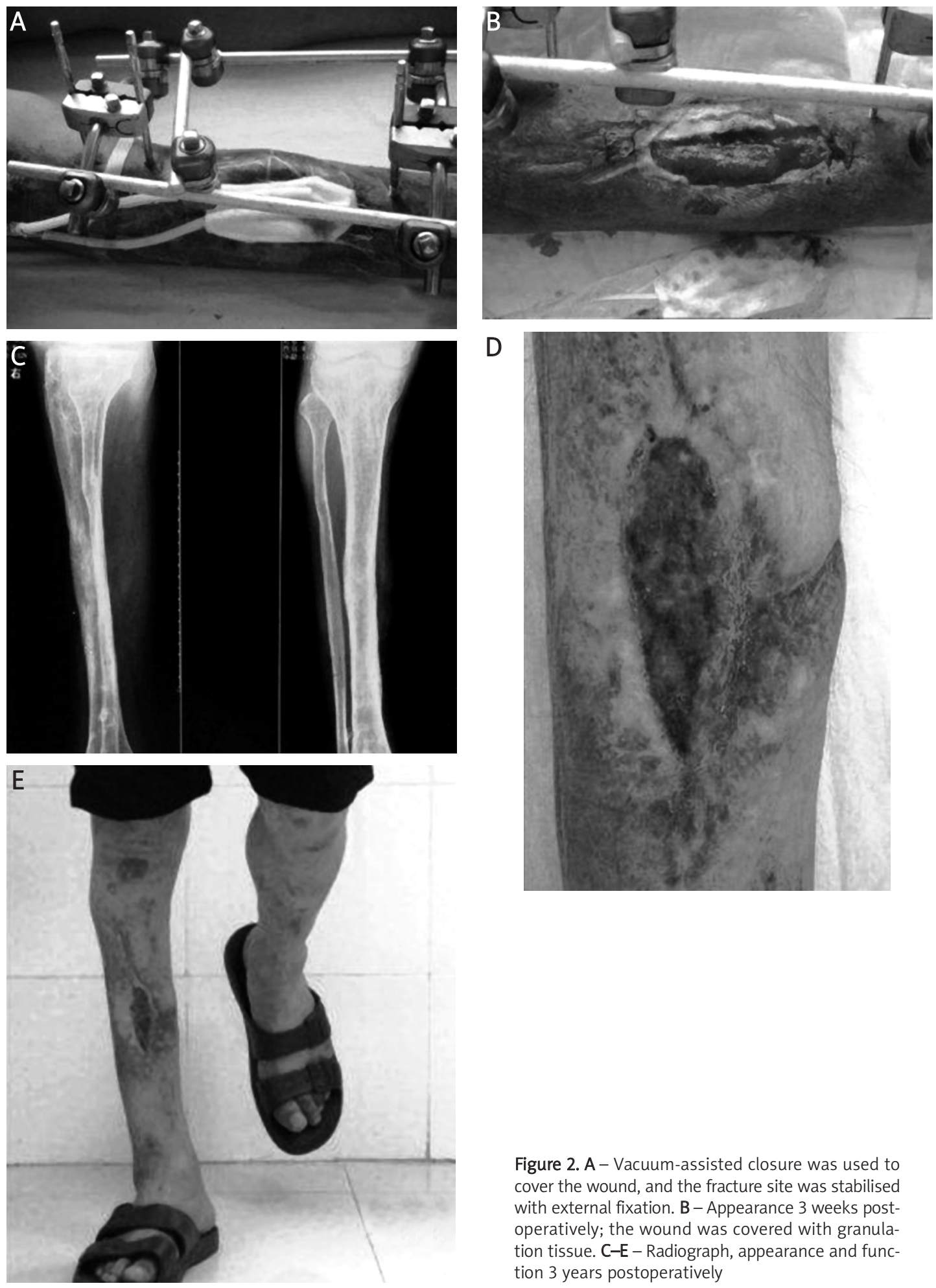

tion, have the ability to span large bony and softtissue defects, and have also yielded satisfactory results. However, the ability to use this option depends on the condition of local blood vessels. Free tissue transfers also represent the highest rung on the reconstructive ladder. They are technically demanding, costly, and time-consuming, with significant complication rates, donor-site morbidity, and

Figure 2. A - Vacuum-assisted closure was used to cover the wound, and the fracture site was stabilised with external fixation. B - Appearance 3 weeks postoperatively; the wound was covered with granulation tissue. C-E - Radiograph, appearance and function 3 years postoperatively

failure rates [20]. The rates of bony union also decrease significantly in the presence of infection [13].

Bone grafting plays a critical role in promoting bone healing in infected tibial non-union, and the open bone grafting technique described by Papineau [2] is an effective treatment alternative. A number of researchers have incorporated new techniques into the procedure, which have 
improved fracture stabilisation, consolidation and the eradication of infection $[3,4,21]$. In his staged techniques for eradicating infection, Papineau advocated open bone grafting with the use of an intramedullary nail to stabilise the non-union, but this has not achieved widespread acceptance. Since external fixation has proven preferable in treatment of infected non-union, some surgeons have modified the Papineau technique using external fixation, with satisfactory outcomes [4, 5, 22]. Stabilisation of infected tibial non-union with external fixation confers the additional advantage of excellent stability following debridement, facilitating further surgery without increasing the risk of infection recurrence $[23,24]$, as well as the ability to maintain the length of the limb if a segment of bone had to be removed. It is also easier to apply and more convenient for wound care. Amongst our patient group, patient 4 refused external fixation as he thought it would cause ankle joint stiffness. The limb was stabilised in plaster when the patient was discharged from hospital. However, the patient later removed the plaster himself and declined further stabilization 1 month later, against the advice of the consulting doctor. The last follow-up revealed tibial non-union with $30^{\circ}$ of varus but no recurrence of infection, and this patient limped without any discomfort. This unsuccessful case confirmed that immobilisation was critical for bone union again. Pin-tract infection is also a common complication in external fixation; 2 patients in this study had minor pin-tract infections that were cured through proper wound care, including daily cleaning of their pin sites with normal saline.

Open bone grafting and external fixation provide an environment for promoting bone union. However, the other problem facing the surgeon is wound care, which is challenging in infected tibial nonunion due to the poor soft-tissue envelope. Traditionally, wet-to-dry dressings were used as wound coverings for this injury $[2,4,25,26]$. However, this increases not only the patients' pain and length of hospital stay, but also the medical staff's workload. This treatment bears the disadvantages of long time of bone union and wound healing. Over the past 15 years a new wound care technology - the VAC - has proven effective in the treatment of complicated wounds [27-29]. Due to a better understanding of lower leg vascular anatomy and better use of improved wound care technology (VAC) there has also been a change in surgical practice, with a trend down the reconstructive ladder, resulting in the use of fewer free flaps and more delayed closures and skin grafts with frequent use of VAC [20]. Various effects of VAC have been proposed, but not all have been confirmed. The mechanisms of action for improved wound healing that can be attributed to VAC therapy are: increased blood flow (human and animal studies); the promotion of angiogenesis (animal studies only); a reduction in the wound surface area (this applies to chronic but not acute wounds); positive modulation of the inhibitory contents in wound fluid (human studies); and the induction of cell proliferation (in vitro and animal studies only) [30]. Somanchi and Khan [31] used a VAC dressing in order to enhance the cover of large soft tissue defects during simultaneous bone transportation in one case of infected tibial nonunion with an osteomyelitic segment of $8 \mathrm{~cm}$. They noted that there was not only remarkable growth of granulation tissue that filled the soft tissue defect and covered the bone, but also satisfactory early signs of bone union across the docking site. These were also present in our study.

Open bone grafting combined with VAC (as used in this study) has the following advantages: (1) It can reduce the quantity of autologous cancellous bone graft required. Elderly patients, patients with chronic alcohol abuse, and some races (e.g. Africans) do not have a large amount of autologous cancellous bone available [25]. In traditional open bone grafting, the vascularization of grafted bone is discouraged. Emami et al. [32] confirmed through PET imaging that there was no evidence of revascularisation of the bone graft within the first week after open bone grafting, and it is inevitable that some portion will be assimilated; therefore, a large amount of bone graft is required. VAC devices can accelerate vascularisation of the grafted bone, and thereby reduce the quantity of bone graft required. (2) This method can shorten the time of bone consolidation. The average time of bone union in infected tibial non-union using the Papineau technique without VAC is $7-15$ months $[4,5,25,33]$. For this method, however, the average time of consolidation was 5.93 months; VAC can encourage bone healing by providing a well-vascularised environment. (3) It can reduce the time needed for wound healing. In our study of 15 patients, wound healing occurred in 5 weeks on average, compared to the average time for traditional open bone grafting of more than 12 weeks [4, 25]. This is because application of the VAC sponge can rapidly produce granulation tissue over exposed bone [34]. (4) For patients with large residual soft-tissue defects after receiving open bone grafting, we could furl the wound margins and suture them to the VAC foam during dressing changes, thus further accelerating the pace of wound closure through mechanical traction. (5) One major problem of treating infected tibial non-union is the risk of infection recurrence. Although antibiotics can penetrate osteomyelitic bone, dead bone or fibrous tissue membranes will often mechanically block it, preventing penetration [35]. The negative pressure of VAC potentially increases the elimination of infected fluid from the 
wound cavity, which is the main cause of infection recurrence [36].

The classic Papineau technique was performed in three main stages, and open bone grafting performed on the basis of a clean wound bed was obtained $[2,25,26]$. The concept of acute bone grafting into a site of chronic infection appeared to be counter-intuitive. However, Liu et al. [37] previously verified the feasibility of one-stage open cancellous bone grafting in the treatment of infected fracture non-unions in a rabbit model. Many surgeons have also confirmed that the onestage procedure can achieve satisfactory outcomes, including a shorter duration of hospitalisation [7, 38-40]. All of those studies emphasised a thorough debridement [7, 37-40], as would be expected, since inadequate debridement increases the risk of recurrence of osteomyelitis and graft failure [3]. Favourable results with this new treatment in our study suggest that one-stage reconstruction with open bone grafting and vacuumassisted closure may be a feasible alternative treatment option for infected tibial non-union. However, it is important not to forget the fundamental benefits provided by a flap in terms of provision of specialised tissue (e.g. muscle, bone, nerves) to aid the functionality and durability of the reconstructed wound. Truly differentiated three-dimensional tissue cannot be provided by filling a defect with granulation tissue followed by placement of a skin graft [28]. In our study, all patients had undergone previous surgery, such as gastrocnemius flap, sural neurocutaneous flap, and cross-leg flap, leading to anatomical disorders in the lower leg. In most cases the soft tissue surrounding the tibia was sterile with cicatrix pasted bone surrounding, and these were not good candidates for free-tissue transfer. Furthermore, 5 patients declined free-tissue transfer. Hence, one-stage reconstruction with open bone grafting and vacuum-assisted closure was recommended for infected tibial non-union where there is the presence of a compromised soft tissue envelope.

In conclusion, this study demonstrated the single-stage treatment of infected tibial non-union with open bone grafting combined with VAC. There are some limitations to our study, including the small sample size $(n=15)$, and the retrospective nature of the analysis (which corresponds to a low level of evidence in the hierarchy of evidence-based medicine). Additional prospective clinical studies with large sample sizes are needed to evaluate the utility of this treatment modality.

\section{Acknowledgments}

This study was supported by the Fundamental Research Funds for the Central Universities (No. 2012303020207)

\section{References}

1. Gershuni DH, Pinsker R. Bone grafting for nonunion of fractures of the tibia: a critical review. J Trauma 1982; 22: 43-9.

2. Papineau LJ. Excision-graft with deliberately delayed closing in chronic osteomyelitis. Nouv Presse Med 1973; 2: 2753-5.

3. Archdeacon MT, Messerschmitt P. Modern papineau technique with vacuum-assisted closure. J Orthop Trauma 2006; 20: 134-7.

4. Saleh M, Kreibich DN, Ribbans WJ. Circular frames in the management of infected tibial non-union: a modification of the Papineau technique. Injury 1996; 27: 31-3.

5. Emami A, Mjöberg B, Larsson S. Infected tibial nonunion. Good results after open cancellous bone grafting in 37 cases. Acta Orthop Scand 1995; 66: 447-51.

6. Ubbink DT, Westerbos SJ, Evans D, et al. Topical negative pressure for treating chronic wounds. Cochrane Database Syst Rev 2008; 3: CD001898.

7. Lei H, Yi L. One-stage open cancellous bone grafting of infected fracture and nonunion. J Orthop Sci 1998; 3: 318-23.

8. Shahcheraghi GH, Bayatpoor A. Infected tibial nonunion. Can J Surg 1994; 37: 209-13.

9. Megas P, Saridis A, Kouzelis A, et al. The treatment of infected nonunion of the tibia following intramedullary nailing by the Ilizarov method. Injury 2010; 41: 294-9.

10. Schöttle PB, Werner CM, Dumont CE. Two-stage reconstruction with free vascularized soft tissue transfer and conventional bone graft for infected nonunions of the tibia: 6 patients followed for 1.5 to 5 years. Acta Orthop 2005; 76: 878-83.

11. Patzakis MJ, Scilaris TA, Chon J, et al. Results of bone grafting for infected tibial nonunion. Clin Orthop Relat Res 1995; 315: 192-8.

12. Brighton CT, Friedenberg ZB, Zemsky LM, et al. Directcurrent stimulation of non-union and congenital pseudarthrosis. Exploration of its clinical application. J Bone Joint Surg Am 1975; 57: 368-77.

13. Bumbasirević $M$, Tomić S, Lesić $A$, et al. War-related infected tibial nonunion with bone and soft-tissue loss treated with bone transport using the Ilizarov method. Arch Orthop Trauma Surg 2010; 130: 739-49.

14. Green SA, Jackson JM, Wall DM, et al. Management of segmental defects by the Ilizarov intercalary bone transport method. Clin Orthop Relat Res 1992; 280: 136-42.

15. Minami A, Kaneda K, Itoga $H$. Treatment of infected segmental defect of long bone with vascularized bone transfer. J Reconstr Microsurg 1992; 8: 75-82.

16. Hou SM, Liu TK. Reconstruction of skeletal defects in the femur with 'two-strut' free vascularized fibular grafts. J Trauma 1992; 33: 840-5.

17. Brighton CT, Black J, Friedenberg ZB, et al. A multicenter study of the treatment of non-union with constant direct current. J Bone Joint Surg Am 1981; 63: 2-13.

18. Brighton CT, Pollack SR. Treatment of recalcitrant nonunion with a capacitively coupled electrical field. A preliminary report. J Bone Joint Surg Am 1985; 67: 577-85.

19. Cattaneo R, Catagni M, Johnson EE. The treatment of infected nonunions and segmental defects of the tibia by the methods of Ilizarov. Clin Orthop Relat Res 1992; 280: 143-52.

20. Parrett BM, Matros E, Pribaz JJ, et al. Lower extremity trauma: trends in the management of soft-tissue reconstruction of open tibia-fibula fractures. Plast Reconstr Surg 2006; 117: 1315-22. 
21. Tulner SA, Schaap GR, Strackee SD, et al. Long-term results of multiple-stage treatment for posttraumatic osteomyelitis of the tibia. J Trauma 2004; 56: 633-42.

22. Green SA, Dlabal TA. The open bone graft for septic nonunion. Clin Orthop Relat Res 1983; 180: 117-24.

23. Ueng WN, Shih $\mathrm{CH}$. Semiopen cancellous bone grafting. A 2 step method for closing small infected tibial bone defects. Clin Orthop Relat Res 1994; 306: 175-82.

24. Petty W, Spanier S, Shuster JJ, et al. The influence of skeletal implants on incidence of infection. Experiments in a canine model. J Bone Joint Surg Am 1985; 67: 1236-44.

25. Panda M, Ntungila N, Kalunda M, et al. Treatment of chronic osteomyelitis using the Papineau technique. Int Orthop 1998; 22: 37-40.

26. Sachs BL, Shaffer JW. A staged Papineau protocol for chronic osteomyelitis. Clin Orthop Relat Res 1984; 184: 256-63.

27. Stannard JP, Singanamala N, Volgas DA. Fix and flap in the era of vacuum suction devices: what do we know in terms of evidence based medicine? Injury 2010; 41: 780-6.

28. Runkel N, Krug E, Berg L, et al. Evidence-based recommendations for the use of negative pressure wound therapy in traumatic wounds and reconstructive surgery: steps towards an international consensus. Injury 2011; 42 Suppl 1: S1-12.

29. Banasiewicz T, Borejsza-Wysocki M, Meissner W, et al. Vacuum-assisted closure therapy in patients with large postoperative wounds complicated by multiple fistulas. Videosurgery Miniinv 2011; 6: 155-63.

30. Mouës CM, Heule F, Hovius SE. A review of topical negative pressure therapy in wound healing: sufficient evidence? Am J Surg 2011; 201: 544-56.

31. Somanchi BV, Khan S. Vacuum-assisted wound closure (VAC) with simultaneous bone transport in the leg: a technical note. Acta Orthop Belg 2008; 74: 538-41.

32. Emami A, Sundin A, Mjöberg B. No recirculation after open cancellous bone grafting. A case examined by positron emission tomography. Clin Positron Imaging 2000; 3: 41-3.

33 Esterhai JL Jr, Sennett B, Gelb H, et al. Treatment of chronic osteomyelitis complicating nonunion and segmental defects of the tibia with open cancellous bone graft, posterolateral bone graft, and soft-tissue transfer. J Trauma 1990; 30: 49-54.

34. DeFranzo AJ, Argenta LC, Marks MW, et al. The use of vacuum-assisted closure therapy for the treatment of lower-extremity wounds with exposed bone. Plast Reconstr Surg 2001; 108: 1184-91.

35. Hedström SA, Lidgren L, Törholm C, et al. Antibiotic containing bone cement beads in the treatment of deep muscle and skeletal infections. Acta Orthop Scand 1980; 51: 863-9.

36. Gordon L, Chiu EJ. Treatment of infected non-unions and segmental defects of the tibia with staged microvascular muscle transplantation and bone-grafting. J Bone Joint Surg Am 1988; 70: 377-86

37. Liu DQ, Zhang BS, Liu HB, et al. Experimental observation of open cancellous bone graft in treatment of infected fracture nonunion. Chin J Orthop Trauma 2004; 6: 1370-3.

38. Chen ZW, Liu H, Zhai WL, et al. Treatment of infected bone defect with one stage open cancellous bone grafting. Zhongguo Gu Shang 2008; 21: 377-8.

39. Lu WJ, Li B, Qian HB, et al. One-stage management of infected nonunion using granulated cancellous bone autografting after debridement. Natl Med J China 2010; 90: 1609-11.

40. Lu WJ, Qian HB, Li B, et al. Treatment of chronic osteomyelitis by modified I-stage open cancellous bone grafting post debridement. Chin J Trauma 2004; 20: 288-90. 